\title{
Reduction of operative mortality after implementation of Surgical Outcomes Monitoring and Improvement Programme by Hong Kong Hospital Authority
}

\author{
WC Yuen, K Wong, YS Cheung, Paul BS Lai *
}

\section{A B S T R A C T}

Introduction: Since 2008, the Hong Kong Hospital Authority has implemented a Surgical Outcomes Monitoring and Improvement Programme (SOMIP) at 17 public hospitals with surgical departments. This study aimed to assess the change in operative mortality rate after implementation of SOMIP.

Methods: The SOMIP included all Hospital Authority patients undergoing major/ultra-major procedures in general surgery, urology, plastic surgery, and paediatric surgery. Patients undergoing liver or renal transplantation or who had multiple trauma or massive bowel ischaemia were excluded. In SOMIP, data retrieval from the Hospital Authority patient database was performed by six full-time nurse reviewers following a set of precise data definitions. A total of 230 variables were collected for each patient, on demographics, preoperative and operative variables, laboratory test results, and postoperative complications up to 30 days after surgery. In this study, we used SOMIP cumulative 5-year data to generate risk-adjusted 30-day mortality models by hierarchical logistic regression for both emergency and elective operations. The

This article was published on $6 \mathrm{Apr}$ 2018 at www.hkmj.org. models expressed overall performance as an annual observed-to-expected mortality ratio. crude mortality rate decreased from $10.8 \%$ to $5.6 \%$ for emergency procedures and from $0.9 \%$ to $0.4 \%$ for elective procedures. From 2011/2012 to 2015/2016, the risk-adjusted observed-to-expected mortality ratios showed a significant downward trend for both emergency and elective operations: from 1.126 to 0.796 and from 1.150 to 0.859 , respectively (MannKendall statistic $=-0.8 ; \mathrm{P}<0.05$ for both).

Conclusion: The Hospital Authority's overall crude mortality rates and risk-adjusted observed-toexpected mortality ratios for emergency and elective operations significantly declined after SOMIP was implemented.
Hong Kong Med J 2018;24:137-44
DOI: $10.12809 / \mathrm{hkmj} 177118$
${ }^{1}$ WC Yuen, FHKAM (Surgery)
${ }^{2} \mathrm{~K}$ Wong, MSc
${ }^{3}$ YS Cheung, FHKAM (Surgery)
${ }^{3}$ PBS Lai *, FHKAM (Surgery)
Department of Surgery, Ruttonjee and Tang Shiu Kin Hospital, Hospital Authority, Hong Kong
Jockey Club School of Public Health and Primary Care, Faculty of Medicine, The Chinese University of Hong Kong, Shatin, Hong Kong of Hong Kong, Shatin, Hong Kong
${ }^{3}$ Department of Surgery, Prince of Wales Hospital, The Chinese University

Results: From 2009/2010 to 2015/2016, the overall * Corresponding author: paullai@surgery.cuhk.edu.hk

New knowledge added by this study

- A Surgical Outcomes Monitoring and Improvement Programme allows monitoring of performance and fair comparison of individual Hospital Authority hospitals against the overall Hospital Authority average. It enhances the understanding of surgical performance and helps identify areas for improvement.

- The Hospital Authority's overall crude mortality rates and risk-adjusted observed-to-expected mortality ratios for emergency and elective operations significantly declined after SOMIP was implemented.

Implications for clinical practice or policy

- A properly organised, risk-adjusted clinical audit can accurately measure surgical outcomes and provide information for surgeons to deliver quality improvement.

\section{Introduction}

Audits of surgical mortality are used worldwide to monitor surgical outcome and achieve quality assurance. ${ }^{1}$ By measuring and comparing properly collected, risk-adjusted surgical outcome data, quality of surgical care could be enhanced in participating institutions. ${ }^{2}$ It has been demonstrated in several countries that adoption of a national surgical audit programme can reduce mortality.,

The Hong Kong Hospital Authority (HA) was established in 1991. It is a government statutory body responsible for the management of 42 public hospitals and institutions, 47 specialist out-patient clinics, and 73 general out-patient clinics in Hong Kong. Seventeen HA hospitals have surgical departments; all of them provide an elective surgery 


\section{醫院管理局實施手術成效監察及改善計劃後減低 手術死亡率 \\ 袁維昌、王家殷、張宇新、賴寶山}

引言：醫院管理局自 2008 年起在本地 17 間設有外科的公立醫院推行「 手術成效監察及改善計劃（SOMIP）」。本研究旨在評估SOMIP對 手術死亡率的影響。

方法：SOMIP的對象包括所有在醫院管理局普通外科、泌尿外科 整形外科和小兒外科進行大型 / 超大型手術的的患者, 而接受肝臟或 腎臟移植, 或有多處創傷或大量腸缺血的患者則例外。六名全職護 士審查員按照一套準確的數據定義, 從醫院管理局病人數據庫中檢索 數據。本研究根據人口統計學資料、術前和手術變量、實驗室檢查 結果以及術後 30 天內併發症收集每名患者的 230 個變量。本研究透過 SOMIP 5年累計數據, 以分層邏輯迴歸法生成經風險調整的緊急和非 緊急手術30天死亡率模型；這些模型亦展示全年總體死亡率的實際預 期比。

結果：2009/2010年至2015/2016年間的整體粗死亡率方面, 緊急手 術由 $10.8 \%$ 降至5.6\%, 非緊急手術則由 $0.9 \%$ 降至0.4\%。2011/2012 年到2015/2016年期間, 緊急和非緊急手術的經風險調整死亡率實際 預期比皆有下降趨勢, 分別由 1.126 跌至 0.796 以及 1.150 跌至 0.859

( Mann-Kendall統計 $=0.8$; 兩者P值皆 $<0.05$ )

結論：SOMIP可顯著改善醫院管理局的緊急及非緊急手術整體粗死亡 率和經風險調整死亡率實際預期比。 service and 14 also provide an emergency surgical service. In 2016 , over $80 \%$ of all hospital admissions in Hong Kong were under the management of the HA. ${ }^{4}$ Therefore, it is important for the HA to develop tools with which to measure and improve performance. For this purpose, the HA Coordinating Committee of Surgery set up a Central Surgical Audit Unit in 2001. From 2002 to 2007, the unit conducted clinical audits based on retrospective cumulative data to compare the performance of the 17 surgical departments. One to two major or ultra-major operations, such as major hepatectomy, oesophagectomy, and major lung resection, were selected each year for comparison. The risk-adjustment model used was based on the Physiological and Operative Severity Score for Enumeration of Mortality and Morbidity (POSSUM). ${ }^{5,6}$ Those audits were procedure-based and mainly focused on mortality, and hence a more comprehensive risk-adjusted outcome audit was needed.

In 2008, a new programme-namely, the Surgical Outcomes Monitoring and Improvement Programme (SOMIP) - was launched by the HA with the aim of monitoring and improving surgical quality. The programme was governed by a steering committee comprising surgeons, an anaesthetist, a physician, administrative managers, and statisticians. Risk-adjusted mortality and morbidity rates of elective and emergency major and ultramajor operations at each hospital are measured and reported yearly. An annual forum is held to disseminate the results and allow the sharing of best practices.

This study aimed to assess the changes in overall surgical outcomes for patients after implementation of SOMIP.

\section{Methods}

Between July 2008 and June 2016, SOMIP captured data of all elective and emergency major/ultra-major operations (except those in children younger than 1 year) that were performed by general surgery, urology, plastic and reconstructive surgery, and paediatric surgery teams at all 17 HA hospitals. A total of 230 variables were collected from each patient: 10 patient demographic variables, 83 preoperative and operative variables, 31 laboratory test results, and 40 postoperative events and 66 postoperative adverse events in the first 30 days after surgery. Demographic data and laboratory test results were mostly automatically retrieved from various HA clinical information systems. For data that required manual retrieval, six full-time SOMIP nurse reviewers were employed by the HA head office for this purpose. Preoperative and operative variables, as well as postoperative complications occurring up to 30 days after the index operation, were retrieved from patient records by the SOMIP nurse reviewers. Mortality at 30 days, 60 days, and 90 days were also retrieved from the HA electronic database. These data were endorsed and submitted by each surgical department's surgical supervisor within 60 days of surgery.

Both the manually captured and automatically captured data were entered into a tailor-made SOMIP electronic database. Data variable definitions were listed in the operation manual of the programme. To ensure data validity and consistency, all nurse reviewers completed comprehensive training on data definition and criteria, and regular nurse reviewer meetings were held to clarify any queries. All data were endorsed by the surgical supervisor of the respective surgical department. When necessary, data definitions were modified.

An inter-rater reliability test was performed each May and completed within a month so as to ensure consistency among nurse reviewers as well as data accuracy. Fifty cases were sampled for evaluation using a stratified systematic sampling method. For those selected cases, an independent nurse from the SOMIP team repeated the data collection using a designated data template, without prior knowledge of the information recorded by the original nurse reviewer. Data quality was measured by comparing two sets of data, and inferred by a score defined 
as the percentage of agreement between nurse reviewer and the SOMIP working team for each data item. The mean score of all data items was used to assess overall performance. The overall result was satisfactory and the mean score of all data items was 99.3\% (range of individual item scores, 95.2\%-100\%).

Among the variables collected, preoperative risk factors including demographic data; general health and lifestyle variables; and major respiratory, cardiovascular, hepatobiliary, renal, vascular, central nervous system, and immune co-morbidities were deemed particularly important. These risk factors were modified from those in the American College of Surgeons National Surgical Quality and Improvement Program (NSQIP) to suit the local context. ${ }^{7-9}$ Operative variables included intra-operative blood loss, American Society of Anesthesiologists physical status classification, procedure complexity score, surgical subspecialty, wound classification, operative magnitude, and operative time. Before analysis and reporting, SOMIP data were cleaned and verified by four surgeons and the SOMIP surgical supervisors of each hospital. Questionable cases were reviewed accordingly. Cases of liver transplantation, renal transplantation, multiple trauma, and major bowel ischaemia (Table 1$)^{10-17}$ were excluded from the riskadjusted model analysis.

Comparative risk-adjusted models (different models for emergency operations and elective operations) were generated using hierarchical logistic regression. The 30-day risk-adjusted mortality models expressed hospital performance as expected odds ratios. A risk-adjusted observedto-expected mortality ratio $(\mathrm{O} / \mathrm{E}$ ratio) was then calculated for each hospital. The $\mathrm{O} / \mathrm{E}$ ratio is a quotient between the observed number of deaths and the expected number of deaths; the latter was calculated by a logistic regression method based on significant independent risk factors. Together with the $90 \%$ confidence intervals, O/E ratios were depicted by caterpillar plots and boxplots. Hospitals with the lower limit of the $90 \%$ confidence interval of $\mathrm{O} / \mathrm{E}$ ratios greater than 1 were defined as 'high outliers'; hospitals with the upper limit of the $90 \%$ confidence interval of $\mathrm{O} / \mathrm{E}$ ratios lower than 1 were defined as 'low outliers'. The risk-adjusted outcome of a 'high-outlier' hospital was probably worse than the average outcome, and that of a 'low-outlier' hospital was probably better than the average outcome.

In addition to risk-adjusted postoperative mortality, various general medical and surgical complications, as well as specific complications (anastomotic leakage, surgical site infection, acute myocardial infarction, pneumonia), were recorded. The list of complications recorded and the method to derive the SOMIP risk-adjustment model have been described in detail in the annual SOMIP Report. ${ }^{10-17}$ Different levels of confidence were used for different outcome variables-90\% confidence interval for mortality rates, 95\% confidence interval for major complications, and 99\% confidence interval for morbidity rates. Using SOMIP data together with other useful information extracted from the HA Executive Information System (eg, bed occupancy, nursing manpower, intensive care unit support, and surgeon workload), root-cause analyses were performed using multilevel logistic regression, as described in the annual SOMIP Report. ${ }^{10-17}$

The discriminative power of the risk-adjusted models was measured by the $\mathrm{C}$-index, area under the receiver-operating characteristic curve (AUC). The closer the $\mathrm{C}$-index is to 1 , the better the discriminative power of the model is: a C-index of $\geq 0.8$ indicates excellent discriminative power. ${ }^{18}$ The calibration accuracy of the models was assessed by the Hosmer-Lemeshow goodness-of-fit test (HL test). The calibration of the model was rejected if $\mathrm{P}<0.05$. The Mann-Kendall non-parametric trend test was used to identify trends (positive or negative) in the annual data series for both crude mortality rates $(2009 / 2010$ to $2015 / 2016)$ and risk-adjusted $\mathrm{O} / \mathrm{E}$ ratios $(2011 / 2012$ to $2015 / 2016)$. A very high positive value of the Mann-Kendall statistic $(S)$ indicated an increasing trend; a very low negative value indicated a decreasing trend. The test statistic $Z$-score was used as a measure of trend significance.

\section{Results}

\section{Descriptive data}

Age distribution trends are summarised in Table 2. ${ }^{10-17}$ From $2008 / 2009$ to $2015 / 2016$, the proportion of people aged 61-70 years increased by 7 percentage points (from $19 \%$ to $26 \%$ ), whereas the proportions

TABLE I. No. of cases excluded and reasons, from $2008 / 2009$ to $2015 / 2016^{10-17}$

\begin{tabular}{lcccccccc}
\hline Reason & $\mathbf{2 0 0 8 / 0 9}$ & $\mathbf{2 0 0 9 / 1 0}$ & $\mathbf{2 0 1 0 / 1 1}$ & $\mathbf{2 0 1 1 / 1 2}$ & $\mathbf{2 0 1 2 / 1 3}$ & $\mathbf{2 0 1 3 / 1 4}$ & $\mathbf{2 0 1 4 / 1 5}$ & $\mathbf{2 0 1 5 / 1 6}$ \\
\hline Liver transplantation & 100 & 76 & 80 & 68 & 79 & 58 & 62 & 58 \\
Renal transplantation & 82 & 65 & 77 & 64 & 103 & 74 & 88 & 66 \\
Multiple trauma & - & - & - & - & 19 & 24 & 98 & 21 \\
Major bowel ischaemia & - & - & - & - & 23 & 20 & 35 \\
\hline
\end{tabular}


of people aged 41-50 years and 71-80 years decreased by 2 and 5 percentage points, respectively.

Table $3^{10-17}$ shows proportions of patients taking regular medication for diabetes mellitus and hypertension before surgery from 2009/2010 to $2015 / 2016$, as well as those currently smoking (within 1 year) and drinking more than 2 units of alcohol per day in the previous 2 weeks. Over $70 \%$ of patients had at least one of these four conditions, whereas about $40 \%$ had a history of regular use of hypertension medication before surgery.

Annual numbers of elective operations by specialty are summarised in Table $4 . .^{10-17}$ For the 10 listed elective operations, the most frequently performed were in urology, consistently constituting $28 \%$ of the caseload from $2008 / 09$ to $2015 / 16$. The least frequently performed procedures were parotid surgery $(1 \%)$ and paediatric surgery $(1 \%)$.

\section{Overall crude mortality rates and risk- adjusted observed-to-expected mortality ratios}

From July 2008 to June 2016, eight SOMIP reports were published. ${ }^{10-17}$ They showed that the HA overall crude mortality rate approximately halved over this time. The crude 30-day mortality rate for emergency operations dropped gradually from $10.8 \%$ in the year $2009 / 2010$ to $5.6 \%$ in $2015 / 2016$ (Fig 1). Similarly, the crude 30-day mortality rate for elective operations more than halved: from $0.9 \%$ in $2009 / 2010$ to $0.4 \%$ in 2015/2016 (Fig 2).

In the 5-year cumulative comparison analysis (2011/2012 to 2015/2016), both models had excellent discriminative power and good calibration accuracy. For emergency operations, the AUC was $>0.9$ and the HL test statistic was $>0.1$; for elective operations, the AUC was $>0.89$ and the HL test statistic was

TABLE 2. Distribution of patients by age-group, from $2008 / 2009$ to $2015 / 2016 .^{10-17 *}$

\begin{tabular}{|c|c|c|c|c|c|c|c|c|c|}
\hline $\begin{array}{l}\text { Age- } \\
\text { group, } \\
\text { y }\end{array}$ & 2008/09 & $2009 / 10$ & $2010 / 11$ & $2011 / 12$ & $2012 / 13$ & $2013 / 14$ & $2014 / 15$ & $2015 / 16$ & Total \\
\hline $1-10$ & 585 (3\%) & 595 (3\%) & $452(2 \%)$ & $538(2 \%)$ & $522(2 \%)$ & $595(2 \%)$ & 565 (2\%) & $569(2 \%)$ & $4421(2 \%)$ \\
\hline $11-20$ & $399(2 \%)$ & $396(2 \%)$ & $366(2 \%)$ & $340(1 \%)$ & $390(2 \%)$ & $343(1 \%)$ & 357 (1\%) & 359 (1\%) & $2950(2 \%)$ \\
\hline $21-30$ & $503(2 \%)$ & 605 (3\%) & $549(2 \%)$ & $590(2 \%)$ & $571(2 \%)$ & $592(2 \%)$ & $660(3 \%)$ & $635(2 \%)$ & 4705 (2\%) \\
\hline $31-40$ & $1181(5 \%)$ & $1214(5 \%)$ & 1187 (5\%) & $1285(5 \%)$ & $1250(5 \%)$ & $1286(5 \%)$ & $1276(5 \%)$ & $1278(5 \%)$ & 9957 (5\%) \\
\hline $41-50$ & 2672 (12\%) & 3057 (13\%) & 2786 (12\%) & 2886 (12\%) & 2783 (12\%) & 2696 (11\%) & 2745 (11\%) & 2671 (10\%) & 22296 (12\%) \\
\hline $51-60$ & 4251 (19\%) & $4680(20 \%)$ & $4599(20 \%)$ & 5095 (21\%) & 5012 (21\%) & $5128(21 \%)$ & 5300 (21\%) & $5433(21 \%)$ & $39498(21 \%)$ \\
\hline $61-70$ & 4253 (19\%) & $4771(20 \%)$ & $4829(21 \%)$ & $5272(22 \%)$ & $5317(22 \%)$ & 5695 (23\%) & 6198 (25\%) & 6604 (26\%) & $42939(22 \%)$ \\
\hline $71-80$ & 5466 (25\%) & 5752 (24\%) & $5486(23 \%)$ & $5341(22 \%)$ & $5104(22 \%)$ & 5064 (21\%) & 5005 (20\%) & 5007 (20\%) & 42225 (22\%) \\
\hline $81-90$ & 2295 (11\%) & 2427 (10\%) & 2833 (12\%) & 2664 (11\%) & 2544 (11\%) & 2661 (11\%) & 2762 (11\%) & 2745 (11\%) & $20931(11 \%)$ \\
\hline $91-100$ & $232(1 \%)$ & $243(1 \%)$ & 293 (1\%) & 226 (1\%) & 227 (1\%) & 258 (1\%) & 225 (1\%) & 226 (1\%) & 1930 (1\%) \\
\hline$>100$ & $2(0 \%)$ & - & $2(0 \%)$ & $7(0 \%)$ & $3(0 \%)$ & $3(0 \%)$ & $6(0 \%)$ & $4(0 \%)$ & 27 (0\%) \\
\hline Total & 21839 (100\%) & $23740(100 \%)$ & $23382(100 \%)$ & 24244 (100\%) & 23723 (100\%) & $24321(100 \%)$ & 25099 (100\%) & 25531 (100\%) & $\begin{array}{l}191879 \\
(100 \%)\end{array}$ \\
\hline
\end{tabular}

* Data are shown as No. (\%) of patients

TABLE 3. Distribution of patients by habit before surgery/admission, from $2009 / 2010$ to $2015 / 2016^{10-17}$

\begin{tabular}{|c|c|c|c|c|c|c|c|c|}
\hline & $2009 / 10$ & $2010 / 11$ & $2011 / 12$ & $2012 / 13$ & $2013 / 14$ & $2014 / 15$ & $2015 / 16$ & Total \\
\hline $\begin{array}{l}\text { Regular diabetes mellitus } \\
\text { medication before operation }\end{array}$ & $3581(15 \%)$ & $3452(15 \%)$ & $3646(15 \%)$ & $3789(16 \%)$ & $3925(16 \%)$ & $3981(16 \%)$ & $4324(17 \%)$ & $26698(14 \%)$ \\
\hline $\begin{array}{l}\text { Regular hypertension } \\
\text { medication before operation }\end{array}$ & $10569(45 \%)$ & $9560(41 \%)$ & $9819(41 \%)$ & $9870(42 \%)$ & $10311(42 \%)$ & $10647(42 \%)$ & $11071(43 \%)$ & $71847(37 \%)$ \\
\hline Current smoker within 1 year & $3428(14 \%)$ & $3593(15 \%)$ & $3903(16 \%)$ & $3823(16 \%)$ & $3892(16 \%)$ & $3982(16 \%)$ & $4226(17 \%)$ & $26847(14 \%)$ \\
\hline $\begin{array}{l}\text { Alcohol }>2 \text { units per day } \\
\text { in the } 2 \text { weeks prior to } \\
\text { admission }\end{array}$ & 777 (3\%) & 709 (3\%) & $707(3 \%)$ & $663(3 \%)$ & $535(2 \%)$ & $499(2 \%)$ & $520(2 \%)$ & $4410(2 \%)$ \\
\hline Total & 18355 (77\%) & $17314(74 \%)$ & $18075(75 \%)$ & $18145(76 \%)$ & 18663 (77\%) & $19109(76 \%)$ & $20141(79 \%)$ & $129802(68 \%)$ \\
\hline
\end{tabular}

\footnotetext{
* Data are shown as No. (\%) of patients
} 
TABLE 4. Elective operations by specialty, from $2008 / 2009$ to $2015 / 2016^{10-17}$

\begin{tabular}{lrrrrrrrrr}
\hline Specialty & \multicolumn{10}{c}{ No. of cases } \\
\cline { 2 - 9 } & $\mathbf{2 0 0 8 / 0 9}$ & $\mathbf{2 0 0 9 / 1 0}$ & $\mathbf{2 0 1 0 / 1 1}$ & $\mathbf{2 0 1 1 / 1 2}$ & $\mathbf{2 0 1 2 / 1 3}$ & $\mathbf{2 0 1 3 / 1 4}$ & $\mathbf{2 0 1 4 / 1 5}$ & $\mathbf{2 0 1 5 / 1 6}$ & Total \\
\hline Lower gastrointestinal surgery & 2124 & 2401 & 2309 & 2447 & 2451 & 2443 & 2593 & 2658 & 19426 \\
\hline Upper gastrointestinal surgery & 576 & 728 & 688 & 646 & 635 & 593 & 645 & 690 & 5201 \\
Vascular surgery & 257 & 300 & 405 & 447 & 433 & 428 & 444 & 466 & 3180 \\
Hepatobiliary surgery & 2637 & 3249 & 3211 & 3337 & 3419 & 3310 & 3355 & 3255 & 25773 \\
Plastic reconstructive surgery & 354 & 462 & 672 & 649 & 618 & 696 & 588 & 601 & 4640 \\
Breast surgery & 1220 & 1227 & 1578 & 1766 & 1692 & 1692 & 1853 & 1797 & 12825 \\
Urology & 3538 & 4185 & 4106 & 4429 & 4314 & 4285 & 4395 & 4482 & 33734 \\
Endocrine surgery & 1611 & 1888 & 2057 & 2077 & 2126 & 2052 & 2083 & 2076 & 15970 \\
Parotid surgery & 184 & 186 & 168 & 144 & 160 & 157 & 158 & 153 & 1310 \\
Paediatric surgery & 129 & 187 & 189 & 208 & 208 & 209 & 183 & 168 & 1481 \\
Total & 12630 & 14813 & 15383 & 16150 & 16056 & 15865 & 16297 & 16346 & 123540 \\
\hline
\end{tabular}

$>0.2$. The risk-adjusted observed-to-expected 30-day mortality ratio for both types of surgery showed a similar downward trend to the crude mortality rates. For emergency operations, the risk-adjusted $\mathrm{O} / \mathrm{E}$ ratios were $1.126,1.022,1.113,0.921$, and 0.796 across the 5 years (Fig 3 ). These values show a statistically significant downward (negative) trend $(S=-0.8 ; \mathrm{P}<0.05)$. The results of the Mann-Kendall analyses are summarised in Table 4. For elective operations, risk-adjusted $\mathrm{O} / \mathrm{E}$ ratios were 1.150, $1.229,0.881,0.862$, and 0.859 across the 5 years (Fig 4). These values show a statistically significant downward (negative) trend $(S=-0.8 ; \mathrm{P}<0.05)$ [Table $5]$.

\section{Discussion}

Before the turn of the century, most hospital records in HA hospitals were handwritten and retained by individual hospitals. There was no convenient means by which to share patient details among hospitals. Around 2001, the HA implemented a number of clinical management electronic systems, such as the electronic patient record, Operation Theatre Record System, and Clinical Data Analysis and Reporting System, at all HA hospitals. By virtue of this infrastructure, patient records and information about diagnoses and operations could be accessed at a central level. Based on this central clinical database, a Quality Assurance Subcommittee under the Coordinating Committee of Surgery commenced small-scale comparative clinical audits for ultramajor operations in 2002, focusing on one to two ultra-major operations per year. The audits provided basic information about hospital performance for the selected operation, such as number of procedures, age distribution of patients, and mortality rate.

Subsequently, the Coordinating Committee of

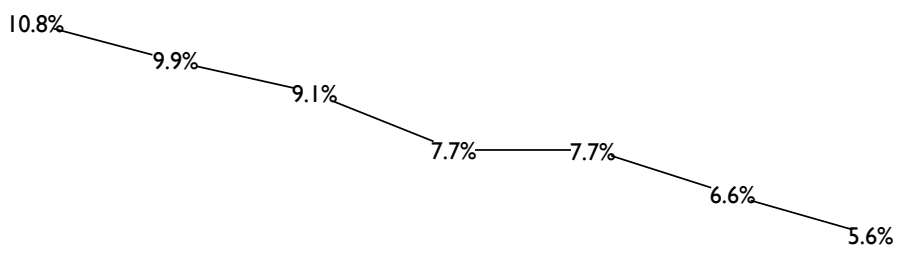

2009/2010 2010/20II 20II/2012 2012/2013 2013/2014 2014/2015 2015/2016

FIG I. Crude 30-day mortality rates for emergency operations, 2009/2010 to $2015 / 2016$

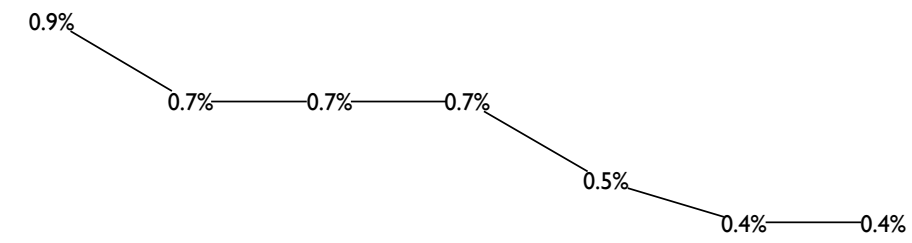

2009/2010 2010/20II 20II/2012 2012/2013 2013/2014 2014/2015 2015/2016

FIG 2. Crude 30-day mortality rates in elective operations, 2009/2010 to $2015 / 2016$

Surgery developed a more robust system to monitor more major operations at the same time. It was decided to follow the framework of NSQIP, which was developed in 1994 by the Veterans Affairs Hospitals 
in the United States to monitor risk-adjusted surgical operation outcomes. Like HA hospitals, Veterans Affairs Hospitals are managed by a central governing body and equipped with a comprehensive electronic medical records system. Studies ${ }^{19,20}$ showed a significant improvement in both mortality

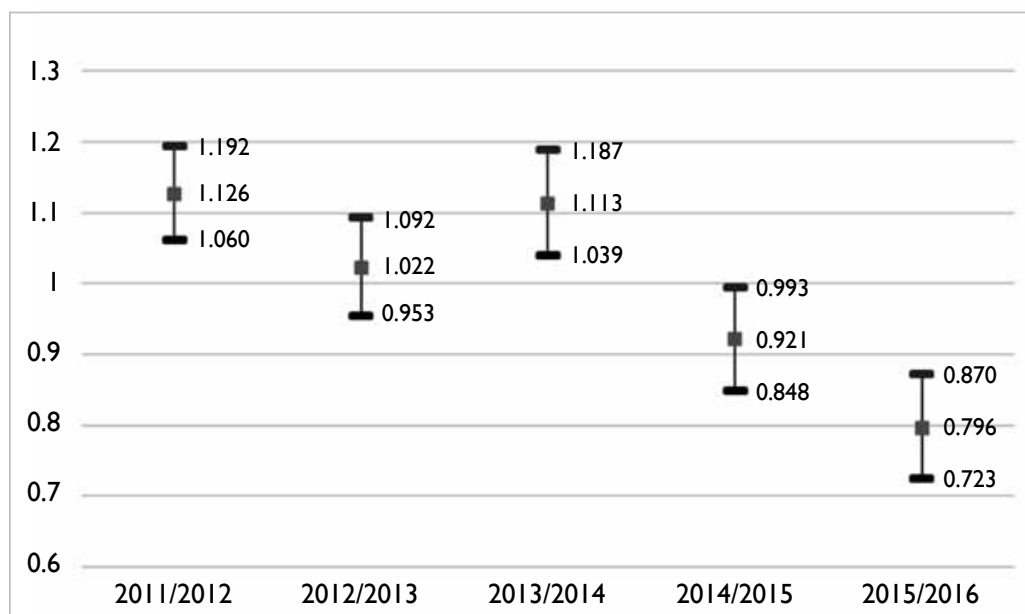

FIG 3. Risk-adjusted observed-to-expected 30-day mortality ratio for emergency operations, $201 \mathrm{I} / 2012$ to $2015 / 2016$ (squares represent odds ratios; vertical lines denote $90 \%$ confidence intervals)

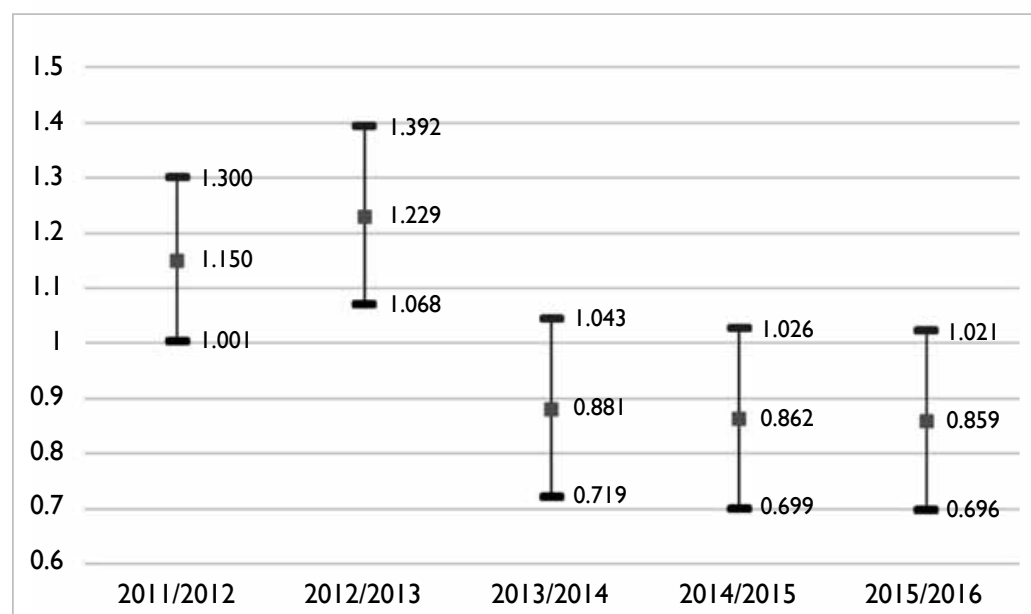

FIG 4. Observed-to-expected 30-day mortality ratio for elective operations, $2011 / 2012$ to $2015 / 2016$ (squares represent odds ratios; vertical lines denote $90 \%$ confidence intervals) and morbidity over time and thus, in 2004, NSQIP was extended to private hospitals and endorsed by the American College of Surgeons. Using NSQIP as the blueprint, the HA launched SOMIP in 2008. The SOMIP adopted similar risk-adjustment variables, use of nurse reviewers to collect data, a focus on hospital performance rather than individual surgeon performance, and similar methods of data analysis and determination of outliers. Moreover, SOMIP allowed individual HA hospitals to benchmark their performance against the overall HA average.

As all surgical patients have a different health status, their operation outcomes will likewise differ. Appropriate adjustment for different patient risks is essential when interpreting hospital mortality rates. To adjust for different risk factors, over 100 patient risk factors were captured for each enrolled patient. For NSQIP, one risk-adjustment mortality model was constructed for all operations. In contrast to NSQIP, separate models were devised for emergency and elective operations in SOMIP.

Hospital outliers can be identified by $\mathrm{O} / \mathrm{E}$ ratios if the confidence interval of the $\mathrm{O} / \mathrm{E}$ ratio is greater than 1 , meaning that after balancing the different risks of hospital patients, their clinical outcomes are most likely different from the rest. From the results of this study, it was encouraging to find a significant trend of reduction in crude mortality rates and $\mathrm{O} / \mathrm{E}$ ratios for both elective and emergency operations at HA hospitals over the past 5 years. According to the significant reduction in expected odds ratios over the years, this improvement is genuine and not due to patient selection.

There are several possible reasons behind the changes: public identification as a poor performer is a strong incentive for change in HA hospitals; sharing best practices on perioperative patient care is an important educational activity that takes place annually through the SOMIP Forum; the HA Head Office invests more resources into deficient hospitals; and changing attitudes towards managing surgical complications by other colleagues from the intensive care unit are also helpful. All of these may have contributed to the change.

\section{Limitations}

The SOMIP has a number of limitations. The coverage of SOMIP is not as complete as that of NSQIP, since many surgical departments such as orthopaedics and

TABLE 5. Mann-Kendall non-parametric trend test results

\begin{tabular}{|c|c|c|c|c|c|}
\hline Type of surgery & $\mathbf{N}$ & $S$ & $\boldsymbol{Z}$ & Trend direction & Trend significance \\
\hline Emergency & 5 & -8.0 & -1.715 & Negative & Yes $(P=0.043)$ \\
\hline Elective & 5 & -8.0 & -1.715 & Negative & Yes $(P=0.043)$ \\
\hline
\end{tabular}


neurosurgery are not included. Monitoring is done by retrospective annual case collection (from 1 July to 30 June) because it takes 13 months to complete case enrolment and an additional 3 months for data verification, model building, and statistical analysis. Because of the small number of events, the current programme is not able to determine the risk-adjusted outcomes of individual operations or surgeons. Furthermore, because this programme relies heavily on the HA central electronic database, it is not easy to extend it to hospitals without this information infrastructure. Although the trend of reduction in mortality was statistically significant, we were not able to demonstrate a causal relationship with SOMIP implementation.

Potential issues with data quality may have affected the outcomes. In the inter-rater reliability test, the nurse reviewers were not blinded and this may have caused information bias. Also, quality of data collection in the initial 2 years may have been unreliable. As a result, the 5-year cumulative comparison analysis for emergency and elective operations commenced from 2011/2012, rather than 2008/2009. Furthermore, data definitions are updated regularly in the operation manual and could have affected the time trend analysis. Nonetheless, the SOMIP team considered changes in data definitions to be minor and did not expect a significant impact on the risk models.

Mortality could be influenced by many factors; ensuring risk adjustments are adequate and appropriate would be a challenge. Disease factors, stage of disease, and treatment options may not be fully taken into account by the risk-adjusted models, and data readiness and availability are further constraints. Surgeon skill and experience was another aspect that could not be accommodated and was difficult to adjust for. In the HA, surgical operations are performed by a team; therefore, it would be difficult to separate individual surgeon experience and credentials from those of the whole team.

\section{Conclusion}

From 2008 to 2016, the HA's overall crude mortality rates and risk-adjusted $\mathrm{O} / \mathrm{E}$ ratios showed a significant trend of reduction for both emergency and elective operations. The SOMIP enhances understanding of surgical performance and helps identify areas for improvement. It allows individual HA hospitals to benchmark their performance against the overall $\mathrm{HA}$ average through risk-adjusted $\mathrm{O} / \mathrm{E}$ ratios.

\section{Acknowledgements}

We thank the SOMIP Steering Committee of the Hospital Authority, the Coordinating Committee of Surgery, and the Biostatistics team of The Chinese
University of Hong Kong for their contributions and helpful comments on this manuscript.

\section{Declaration}

The authors have no conflicts of interest to disclose.

\section{References}

1. Lui CW, Boyle FM, Wysocki AP, et al. How participation in surgical mortality audit impacts surgical practice. BMC Surg 2017;17:42.

2. Khuri SF, Daley J, Henderson W, et al. Risk adjustment of the postoperative mortality rate for the comparative assessment of the quality of surgical care: results of the National Veterans Affairs surgical risk study. J Am Coll Surg 1997;185:315-27.

3. Kiermeier A, Babidge WJ, McCulloch GA, Maddern GJ, Watters DA, Aitken RJ. National surgical mortality audit may be associated with reduced mortality after emergency admission. ANZ J Surg 2017;87:830-6.

4. Hospital Authority Statistical Report (2015-16). Available from: http://www.ha.org.hk/haho/ho/stat/HASR15_16. pdf. Accessed 10 Nov 2017.

5. Copeland G, Jones D, Walters M. POSSUM: A scoring system for surgical audit. Br J Surg 1991;78:355-60.

6. Copeland G. The POSSUM system of surgical audit. Arch Surg 2002;137:15-9.

7. Khuri S, Daley J, Henderson W, et al. The National VA Surgical Risk Study: risk adjustment for the comparative assessment of the quality of surgical care. J Am Coll Surg 1995;180:519-31.

8. Daley J, Khuri SF, Henderson W, et al. Risk adjustment of the postoperative morbidity rate for the comparative assessment of the quality of surgical care: results of the National Veterans Affairs surgical risk study. J Am Coll Surg 1997;185:328-40.

9. Daley J. Validating risk-adjusted surgical outcomes: site visit assessment of process and structure. J Am Coll Surg 1997;185:341-51.

10. Surgical Outcomes Monitoring \& Improvement Program (SOMIP) report. Volume One: July 2008-June 2009. Hospital Authority, Hong Kong SAR Government; 2010.

11. Surgical Outcomes Monitoring \& Improvement Program (SOMIP) report. Volume Two: July 2009-June 2010. Hospital Authority, Hong Kong SAR Government; 2011.

12. Surgical Outcomes Monitoring \& Improvement Program (SOMIP) report. Volume Three: July 2010-June 2011. Hospital Authority, Hong Kong SAR Government; 2012.

13. Surgical Outcomes Monitoring \& Improvement Program (SOMIP) report. Volume Four: July 2011-June 2012. Hospital Authority, Hong Kong SAR Government; 2013.

14. Surgical Outcomes Monitoring \& Improvement Program (SOMIP) report. Volume Five: July 2012-June 2013. Hospital Authority, Hong Kong SAR Government; 2014.

15. Surgical Outcomes Monitoring \& Improvement Program (SOMIP) report. Volume Six: July 2013-June 2014. Hospital Authority, Hong Kong SAR Government; 2015.

16. Surgical Outcomes Monitoring \& Improvement Program (SOMIP) report. Volume Seven: July 2014-June 2015. Hospital Authority, Hong Kong SAR Government; 2016.

17. Surgical Outcomes Monitoring \& Improvement Program (SOMIP) report. Volume Eight: July 2015-June 2016. Hospital Authority, Hong Kong SAR Government; 2017. 
18. Ash A, Schwartz M. Evaluating the performance of riskadjustment methods: dichotomous variables. In: Iezzoni L, editor. Risk adjustment for measuring health care outcomes. Ann Arbor, MI: Health Administration Press; 1994: 313-46.

19. Hall BL, Hamilton BH, Richards K, Bilimoria KY, Cohen ME, Ko CY. Does surgical quality improve in the
American College of Surgeons National Surgical Quality Improvement Program: An evaluation of all participating hospitals. Ann Surg 2009;250:363-76.

20. Cohen ME, Liu Y, Ko CY, Hall BL. Improved surgical outcomes for ACS NSQIP hospitals over time: evaluation of hospital cohorts with up to 8 years of participation. Ann Surg 2016;263:267-73. 